\author{
Mayza Izadora Lora ${ }^{1}$ \\ Cristiane Maria Tonetto Godoy ${ }^{2}$ \\ Wilson Itamar Godoy ${ }^{3}$ \\ Marcos Junior Marini ${ }^{4}$
}

\title{
Tecnologias de Informação e Comunicação, o outro viés da sustentabilidade: um olhar para o rural do município de Saudade do Iguaçu (PR)
}

\section{Introdução}

O modelo de desenvolvimento como sinônimo apenas de crescimento econômico e com base na larga utilização dos recursos levou a sociedade a uma crise social e ambiental. Dessa forma, nas últimas décadas tem se buscado alternativas de desenvolvimento que englobem outras dimensões, que não somente a ótica econômica. O desenvolvimento passa a ser compreendido como algo complexo e multidimensional, sendo construído por diversos elementos e fatores, tais como: cultura, meio ambiente, social, econômico, entre outros. Em outras palavras, não segue uma lógica linear e simplória. Neste sentido, com a tomada da consciência da existência desses outros fatores é que surge a noção de sustentabilidade e de desenvolvimento sustentável, esses como alternativa ao modelo de desenvolvimento vigente.

O termo desenvolvimento sustentável vem a ser disseminado a partir da publicação do Relatório de Brundtland, no ano de 1987, escrito pela Comissão Mundial de Meio Ambiente e Desenvolvimento (CMMAD), e no

\footnotetext{
${ }^{1}$ Mestrado em Desenvolvimento Regional (Ambiente e Sustentabilidade) pela Universidade Federal Tecnológica do Paraná (UFTPR). E-mail: mayza_lora@hotmail.com.

2 Doutorado no Programa de Pós-Graduação em Extensão Rural e bolsista pós-doc do Programa de Pós-Graduação em Desenvolvimento Regional da Universidade Federal Tecnológica do Paraná (UTFPR). Email: guriaccr@hotmail.com.

3 Doutorado em Agronomia pela Universidade Federal de Pelotas (UFPel) e professor associado nível 2 no Curso de Agronomia da Universidade Federal Tecnológica do Paraná (UTFPR). E-mail: wigodoy@utfpr.edu.br.

${ }^{4}$ Doutorado em Tecnologia, professor do Programa de Pós-Graduação em Desenvolvimento Regional (PPGDR) da Universidade Federal Tecnológica do Paraná (UFTPR) e pesquisador dos grupos de pesquisa "Centro de Pesquisa e Apoio ao Desenvolvimento Regional" e "Políticas Públicas e Dinâmicas de Desenvolvimento Territorial". E-mail: marini@utfpr.edu.br.
} 
Brasil ficou conhecido como "Nosso Futuro Comum". De acordo com o relatório, o conceito de desenvolvimento sustentável deve ser compreendido como "aquele desenvolvimento que atende às necessidades do presente sem comprometer as possibilidades de as gerações futuras atenderem às suas próprias" (COMISSÃO MUNDIAL SOBRE MEIO AMBIENTE E DESENVOLVIMENTO, 1988).

Entretanto, a maioria das propostas e projetos com o viés sustentável tem mantido o foco na questão ambiental, na conservação, preservação e na economia aliada ao meio ambiente. Assim, o elemento social e as demais dimensões ficam simplificados ou marginalizados nas discussões, políticas públicas e nas pesquisas científicas.

Ao tomarmos como base a reflexão feita na década de 1990 por Sachs (1993), teremos a dimensão social compreendida por diversos fatores, tais como: a melhoria da qualidade de vida da população, o fim da desigualdade social, a inclusão social, a participação, o acesso à saúde, à educação, à segurança alimentar e nutricional, à habitação, à seguridade social, entre outros. Para Foladori (2002), dentro da discussão sobre sustentabilidade no seu viés social, as temáticas sobre a participação social são uma das mais relevantes, pois para o autor a participação seria um indicador de liberdade democrática e de equidade nas decisões da sociedade.

Podemos refletir que o acesso às decisões e à liberdade democrática leva ao empoderamento da população; as informações não seriam somente com caráter elucidativo, mas passariam a ter um viés educativo, emancipador e deliberativo. Esses condicionantes fariam com que a sociedade analisasse e discutisse quais as diretrizes e qual o projeto balizador do seu desenvolvimento, considerando os anseios e as culturas de cada população. Porém, é necessário que esses condicionantes sempre tenham a orientação da sustentabilidade, pois ela deve ser o elemento balizador de todas as ações e atividades humanas, para assim garantir um meio equilibrado e que permita a sobrevivência dos ecossistemas (homo sapiens como elemento dessa rede).

Nesse panorama de qualidade de vida e de relações sociais, teremos a presença da tecnologia na sociedade globalizada, conceitualmente denominada Tecnologias de Informação e Comunicação (TICs), o que atualmente contempla principalmente as ferramentas da telefonia e da internet. $\mathrm{O}$ acesso a essas tecnologias visa encurtar as distâncias pela comunicação mais ágil e eficaz, bem como facilitar a transferência e mobilidade de informações e conhecimento entre os indivíduos. Colaborando:

A implantação das tecnologias de informação e comunicação no cenário social está cada vez mais acelerado e crescente, tendo mudanças significativas em um curto espaço de tempo. Nesse 
sentido, surgem estudos que concordam com os benefícios da expansão da tecnologia e outros apontam que essas mudanças evidenciam uma ruptura de ideais sociais, culturais, econômicas e políticas. Para tanto, não se pode negar que as TICs contribuíram significativamente para a evolução dos mais diversos segmentos de mercado na sociedade, para a comunicação ágil e eficaz, dispondo de várias ferramentas para serem utilizadas na informação e comunicação em tempo real. (GUSTMANN; BERNARTT; GODOY, 2017, p. 165)

Compreendemos que a sustentabilidade social engloba, também, o elemento de uso e acesso das tecnologias de informação e comunicação, sendo um indicador da liberdade, bem-estar e de desenvolvimento de determinada população. A garantia a essa tecnologia se torna um direito elementar na sociedade moderna e a falta ou deficiência desse direito afeta diretamente a qualidade de vida dos usuários, surgindo assim desafios e lutas para garantir a disponibilização das TICs.

Nesse aspecto, nem todas as regiões terão acesso aos serviços de telefonia e internet, por exemplo, aquelas áreas com condições socioeconômicas baixas, as áreas remotas ou as áreas rurais. Pensar a sustentabilidade em seu aspecto social, no que tange às TICs, só será efetivado quando seus elementos forem disponibilizados tanto para as áreas urbanas quanto para as áreas rurais. Ainda, o acesso a essas tecnologias é de suma importância na efetivação do desenvolvimento rural sustentável e para a reprodução da agricultura familiar.

O presente artigo tem como objetivo compreender a percepção dos agricultores familiares do município de Saudade do Iguaçu, Paraná, no que se refere à qualidade e ao acesso à telefonia e à internet no meio rural, bem como qual seria a importância desses serviços na reprodução social e no desenvolvimento rural sustentável. Como justificativa, entendemos que as TICs constituem uma estratégia para a permanência e reprodução social da agricultura familiar, principalmente para os jovens. Acreditamos que tal reflexão traga novos elementos a essa discussão, assim como oriente novas ações e projetos para o rural.

\section{Conhecendo o aporte metodológico}

O município de Saudade do Iguaçu está situado na porção sudoeste do estado do Paraná. De acordo com o Censo de 2010, a população estimada é de 5.444 habitantes e, destes, 2.507 vivem no meio rural, enquanto a população urbana seria de 2.500 habitantes, e a economia do município está baseada no comércio e na agricultura (IBGE, 2017). Assim, podemos determinar que o município apresenta uma área rural representativa perante o urbano, tanto economicamente quanto socialmente. Corroborando, Ipardes (2017) traz que a matriz econômica de Saudade do Iguaçu consiste em atividades relacionadas à pecuária e à agricultura, 
tendo a soja como cultura principal e o rebanho bovino destinado ao leite, além da agricultura familiar.

Para compreender e interpretar a realidade social (as relações e os seus significados), optamos pela abordagem qualitativa, tipicamente usada nas Ciências Sociais. Desse modo, partimos do pressuposto de que os elementos que formam a sustentabilidade devem ser aferidos e compreendidos não somente através da quantificação, mas também a partir de dados que expressem qualitativamente a complexidade das relações.

Dentre os diversos métodos da pesquisa qualitativa, a entrevista semiestruturada aproxima o pesquisador e o entrevistado, deixando esse último à vontade para expressar suas opiniões e percepções. Conforme Fujisawa (2000), a entrevista semiestruturada é uma das técnicas guiada a partir de um roteiro de questões, que permite ao pesquisador realizar mudanças e flexibilizações à medida que as informações vão sendo originadas, enriquecendo a pesquisa com detalhes.

Entretanto, cabe ressaltar que os estudos qualitativos podem incluir apenas um respondente ou uma fonte de dados, o que é suficiente para uma análise (LINCOLN; GUBA, 1991). Corroborando, Ribeiro, Souza e Lobão (2018) afirmam que não existe um regramento que determine a quantidade específica de dados para as pesquisas de cunho qualitativo. Nesse tipo de metodologia, a informação que se busca não está propriamente na quantidade do número de entrevistas e sim na qualidade, profundidade e na extensão das respostas dadas pelos entrevistados.

Nesse sentido, para compreender a percepção sobre a qualidade e o acesso aos serviços de telefonia e internet foram realizadas entrevistas semiestruturadas com 26 agricultores familiares do município de Saudade do Iguaçu. As perguntas estavam relacionadas aos aspectos sociais, econômicos e ambientais das propriedades. Cabe salientar que a seleção de entrevistados não foi pautada em nenhum estilo de delineamento estatístico.

As entrevistas foram realizadas com os agricultores familiares no mês de junho de 2017 e com todos que participavam de palestras promovidas pela Prefeitura em conjunto com docentes do curso de Agronomia da Universidade Tecnológica Federal do Paraná, campus Pato Branco. As palestras foram pensadas a partir das demandas levantadas pelos próprios agricultores, abrangendo as temáticas de solos, cooperativismo e águas. Essa construção em conjunto se baseia no papel social da Universidade, por meio da extensão, visando ao atendimento à comunidade, bem como compreendendo uma prática que interliga as trocas de conhecimentos, aliando nesse momento o ensino e a pesquisa. 
Para este artigo, foram usados os seguintes questionamentos: Como é o sinal e o acesso à internet e à telefonia móvel? Faz uso das redes sociais, tais como WhatsApp e Facebook? Como e qual(is) é(são) o(s) principal(is) meio(s) de comunicação que utiliza para informações e novidades na comunidade?

Para as avaliações das respostas, foram seguidos os seguintes passos: (a) análise dos sentidos e significados das respostas dos agricultores; (b) interpretação das percepções pelos pesquisadores e articulação com outros estudos e pesquisas. Essa metodologia foi pensada para que se pudesse ter o mínimo de indicadores qualitativos para compreender a realidade da presença das Tecnologias de Informação e Comunicação no meio rural.

\section{Tecnologias de Informação e Comunicação: como está nosso rural?}

A noção de um desenvolvimento sustentável rural parte do pressuposto de uma matriz produtiva que possibilite a sustentabilidade dos agroecossistemas, que seja rentável economicamente e englobe socialmente os agricultores familiares. Nesse contexto, esse modelo de desenvolvimento, além da conservação e preservação ambiental, propicia a permanência e a reprodução da agricultura familiar no rural, através da valorização destas para a produção de alimentos mais limpos e saudáveis.

Pensar a sustentabilidade somente sob os aspectos ambientais e econômicos faz com que esse paradigma seja insustentável, pois a qualidade de vida das populações e os seus diversos direitos e culturas devem ser considerados; caso contrário, entraremos novamente em uma crise social e ambiental. Corroborando, Almeida (2009), ao analisar a noção de desenvolvimento sustentável, aponta que ele permite que os sistemas sejam integrados, isto é, se incorporem nessa perspectiva de exploração dos recursos naturais, avanço tecnológico e mudança social.

Assim, podemos aferir que a tecnologia surge como uma aliada ao desenvolvimento, buscando, principalmente, a melhoria nas relações sociais. Foi especialmente entre as décadas de 1970 e 1990 que ocorreram as principais mudanças no campo tecnológico e comunicacional. Para Pereira e Silva (2012), houve uma revolução em todo o sistema social, em escala mundial, promovendo o desenvolvimento a partir da adoção imediata da tecnologia, conectando as regiões em nível mundial, o que foi denominado de Sociedade da Informação.

$\mathrm{O}$ termo tecnologia denota uma concepção de produção do conhecimento centrado na técnica, vindo a auxiliar na construção do saber de forma coletiva, e que possibilita intervenções com caráter intencional. De acordo com Felippi e Escosteguy (2017), as TICs podem ser compreendidas por aquelas mídias tradicionais, tais como jornais, revistas, rádio e televisão, como também pelas novas mídias, que 
englobam o celular, o smartphone, os computadores e a internet. Essas tecnologias acabaram por ser onipresentes na sociedade contemporânea e, de certa forma, se tornaram elementos para as mudanças sociais e culturais.

As TICs tornaram-se uma revolução nas formas de executar atividades nos mais variados tipos de negócios, mercados, na gestão de recursos, tudo isso por ofertar serviços inovadores, eficientes e diversos. Portanto, é comum encontrarmos cada vez mais uma gama maior de pesquisas na área das TICs, pois a sua adoção nos mais diversos meios é crescente, levando à criação de novas estratégias e tornando-se importante na construção/transmissão do conhecimento, acima de tudo para as pessoas que vivem no campo, "ampliando os horizontes tanto na zona urbana, quanto na zona rural" (LAMARCA et al., 2017, p. 59).

De acordo com Gustmann, Bernartt e Godoy (2017), não há dúvida que a atual sociedade apresenta grandes avanços tecnológicos, o que possibilita conquistar o espaço em tempo veloz, modificando e impactando a sociedade globalizada. As autoras afirmam que vivemos em uma sociedade da informação, em que o acesso aos meios de comunicação e informação acontece em tempo real e de forma dinâmica. Segundo Castells (1999), com o desenvolvimento da comunicação eletrônica, experimentamos a crescente dissociação entre a proximidade espacial e as nossas funções rotineiras. $\mathrm{O}$ avanço tecnológico permitiu a interação e a comunicação de forma mais fluída, bem como a permanente possibilidade de interação pelo acesso digital.

Para Felizola (2011), o encurtamento das distâncias e a evolução das telecomunicações são apenas algumas das mudanças vividas pela sociedade, e as TICs são um novo paradigma social. $O$ acesso à comunicação e á informação acabam por se tornar um direito fundamental dos indivíduos e cabe ao Estado, por meio de políticas públicas, garantir e ampliar os serviços dessas tecnologias, em especial a telefonia móvel e a banda larga.

De acordo com Leite e Fiorillo (2016), as tecnologias da comunicação fazem parte do meio ambiente cultural, sendo assim uma das dimensões da sustentabilidade. Nesse contexto, o uso de TICs passa a auxiliar na construção de políticas e projetos com bases sustentáveis. Nas palavras dos autores:

O uso de ferramentas tecnológicas, como a internet, pode conferir suporte para manifestações de diferentes ordens, tais como as realizadas por comunidades indígenas, quilombolas e outros atores individuais e coletivos. Ao mesmo tempo, iniciativas estatais ou ainda promovidas a partir das corporações podem ser divulgadas, de modo a facilitar o diálogo interno e externo de cada nação. Por tais razões, o reconhecimento desses diversos processos de globalização atua como um reforço à cidadania, porque evidencia a 
participação de todos, fundamento essencial do Direito Ambiental para a busca de uma sadia qualidade de vida. (2016, p. 344)

Para Wammes, Pastório e Roesler (2013), o desenvolvimento sustentável e suas atuais perspectivas apontam para a promoção do direito à equidade, à participação e ao empoderamento da população. A participação está diretamente ligada ao exercício da cidadania e à tomada das decisões sociais, econômicas e ambientais, o que é de suma importância para o fortalecimento desse espaço para a sustentabilidade.

Nesse contexto, podemos aferir que o uso das tecnologias de informação e comunicação na sociedade moderna permite aos indivíduos mais participação, sendo uma ferramenta estratégica para o empoderamento da sustentabilidade. Para Abreu et al. (2016, p. 156), apenas se o sujeito participar da sociedade é que será possível transformar a realidade existente, reduzindo assim as desigualdades sociais e construindo o processo de protagonismo.

Dessa forma, "a difusão das TICs, especialmente da internet, tornou-se uma necessidade para o meio rural, tanto quanto já era para o urbano, visando atender à demanda por conhecimento e informações atualizadas e constantes" (VIERO; SILVEIRA, 2011, p. 259). Entretanto, ainda nos dias atuais, nem todos possuem acesso a esses meios de comunicação, e quando têm, ele é de forma precária, como ocorre em regiões desassistidas que, na maioria das vezes, são as áreas urbanas periféricas e as áreas rurais. De acordo com Takahashi (2000), para não se criar uma classe de pessoas excluídas do acesso à informação e à comunicação, se torna fundamental a busca de alternativas que sejam realmente eficazes e que abranjam os diferentes públicos, dentre as diferentes localidades.

Para compreender a realidade das TICs no rural do município de Saudade do Iguaçu e termos a percepção sobre o fornecimento desses serviços, perguntamos aos agricultores familiares se eles teriam acesso ao serviço de telefone móvel e à internet em suas propriedades, como apresentado na Tabela 1. Ainda, indagamos sobre a qualidade do sinal prestado pelas operadoras de telefonia e de internet, conforme Tabela 2. Cabe salientar que alguns agricultores durante a aplicação do questionário não responderam a certas perguntas e, por essa razão, alguns valores não foram contemplados com as 26 respostas.

Tabela 1 - Acesso à telefonia e à internet

\begin{tabular}{c|c}
\hline Respostas & Número de Famílias \\
\hline Acesso a Telefonia móvel & 25 \\
\hline Acesso à Internet & 15 \\
\hline Sem acesso à Internet & 10 \\
\hline
\end{tabular}

Fonte: Os autores, 2017. 
Tecnologias de Informação e Comunicação, o outro viés da sustentabilidade...

Tabela 2 - Qualidade do sinal do serviço

\begin{tabular}{lc|cc}
\hline Respostas & Ruim & Bom & Sinal através de antena em casa \\
\hline Telefonia móvel & 5 & 10 & 4 \\
\hline Internet & 6 & 4 & - \\
\hline
\end{tabular}

Fonte: Os autores, 2017.

Em relação às respostas, podemos perceber que a telefonia móvel é a que está mais presente nas propriedades, e os 25 agricultores têm acesso. Porém, ao verificarmos a qualidade do sinal, 10 agricultores consideraram boa, quatro agricultores conseguem sinal pelo uso de antenas nas propriedades, e não por meio do serviço prestado pelas operadoras de telefonias no país, e cinco agricultores responderam que o sinal é ruim.

Quanto à prestação de serviço e do sinal, os agricultores relataram que somente conseguiam sinal de uma operadora de telefonia, as demais não possuem sinal na área rural das propriedades (considerando que teríamos pelo menos quatro operadoras principais no Brasil). Para ilustrar esses dados, apresentamos alguns relatos dos agricultores sobre o acesso da telefonia móvel em suas propriedades, nas suas comunidades e a situação do acesso às ferramentas tecnológicas de informação: "[...] o telefone celular pega, não dá para se queixar" (Entrevista 22); "[...] celular só com antena" (Entrevista 14); "sinal de telefone é ruim, o celular dificilmente pega" (Entrevista 23).

Em estudo realizado por Schwartz (2007) sobre as TICs existentes no meio rural, observamos que os telefones fixos estavam sendo trocados pelo uso dos celulares, sendo estes um equipamento recorrente nas propriedades rurais. Esse fato se dá principalmente pela facilidade de chamadas por programas de comunicação - exemplo, o Skype (atualmente via WhatsApp) -, e que esses não gerariam cobrança para quem os usa. Porém, a autora salienta que a área rural, no ano de 2006, era a que menos possuía acesso ao telefone com utilização da rede virtual no país.

A pesquisa acima foi realizada em 2006, o que nos faz pensar que o acesso ao sinal de celular melhorou no decorrer dos anos seguintes. Entretanto, na reportagem divulgada no final de 2017, essa realidade continua a mesma, o que corrobora as respostas dadas pelos agricultores familiares de Saudade do Iguaçu (PR). De acordo com a reportagem, as empresas de telefonias brasileiras assumiram, no ano de 2012, com a Agência Nacional de Telecomunicações (Anatel), a obrigação de fornecer o serviço de telefonia móvel e aumentar a frequência do sinal para todas as áreas rurais no Brasil. Contudo, após cinco anos, não houve o cumprimento do acordo, o que segundo as empresas se deve à preocupação em atender as áreas urbanas com a tecnologia $4 \mathrm{G}$, e por isso 
não tiveram tempo e capital para investir nas áreas rurais (FOLHA DE SÃO PAULO, 2017).

Em relação à internet, 15 agricultores possuem acesso e 10 responderam que ainda não tinham acesso ao sinal da rede, quatro agricultores responderam que o sinal é bom, mas seis agricultores responderam que o sinal é ruim, sendo que a maioria do serviço prestado é feita por sinal via rádio. Para exemplificar, apresentamos algumas falas que abordam essa questão: "Internet é via rádio, sinal ruim" (Entrevista 22); "Sinal mais ou menos, internet fraca" (Entrevista 15); "A internet é via rádio, com sinal mais ou menos [...] dá para usar" (Entrevista 24).

$\mathrm{Na}$ pesquisa realizada por Freitag (2015), foi registrado que para os agricultores que vivem em áreas mais remotas o acesso a uma internet de qualidade é difícil, acarretando a escolha da internet via rádio. Segundo o autor, a internet via rádio é utilizada por ter um baixo custo de manutenção e apresentar boas taxas de preço e velocidade. Mata (2016), ao elucidar sobre a internet via rápida, diz que esse tipo de transmissão é mais vantajoso nas cidades pequenas do que nas grandes cidades, devido aos inúmeros prédios que impedem o sinal da antena com o receptor, pois quanto mais empecilhos pior será o sinal. Da mesma forma, o funcionamento da antena e da transmissão até o receptor não passará através dos morros; essa informação explica o sinal ruim existente nas áreas rurais do Paraná, já que o relevo desse estado possui vários morros e serras. Os autores corroboram a afirmação presente na reportagem supracitada, que traz o descumprimento das empresas de telefonia e internet em relação à prestação dos serviços nas áreas rurais, ficando para outros segmentos o fornecimento dessas TICs, nem sempre com sinal de qualidade.

Ao relacionarmos a realidade existente no município com o papel das tecnologias na construção do conhecimento e na inovação de alternativas produtivas, recorremos à pesquisa de Rocha et al. (2014). Para os autores, é reconhecida a importância da política nacional de inovação para a agricultura e o desenvolvimento rural, sendo a tecnologia o instrumento principal nesse processo, constituindo assim uma estratégia vital para a sustentabilidade. Conforme Filho (2009), os acessos aos serviços de banda larga nos últimos anos deveriam merecer atenção especial das autoridades brasileiras. Esse é um tema importante a ser tratado em uma próxima pesquisa, visando avaliar a disponibilidade desses serviços nas comunidades rurais, analisando-se os preços de manutenção e taxas mensais.

Retomando os dados obtidos, verificamos que uma grande parcela dos agricultores conta com um serviço de telefonia e internet precário, e se relacionarmos esse fato com a pretensão de alcançar o desenvolvimento rural sustentável, veremos que isso se torna inviável e impossível. Nesse 
sentido, quando colocamos o papel das atuais tecnologias de comunicação e informação para a geração de inovações e o acesso à informação, no que tange à disseminação do conhecimento, observamos que o rural está desassistido e longe da realidade vivida pelos centros urbanos.

E como devemos pensar a permanência dos jovens e a reprodução da agricultura familiar com esse panorama? Partimos do pressuposto de que um dos principais fatores que poderiam auxiliar na permanência do jovem no campo seria o direito ao acesso às mídias atuais, o que faria com que ele não abandonasse o meio rural para encontrar melhores condições e acesso aos recursos tecnológicos. De acordo com Ricoy e Couto (2014), as TICs promovem mudanças importantes na vida das pessoas, pois facilitam a prática, os serviços e o acesso ao conhecimento.

As redes servem como via para o desenvolvimento sustentável, e, segundo Neiva (2010), elas contribuem para a construção social, demandando a participação e responsabilidade de todos os envolvidos. Ainda corroborando o tema:

A mudança de paradigmas que o surgimento da Rede trouxe para o mundo acabou por trair os conceitos de comunidades tradicionais. Não há interação física. Não há proximidade geográfica: Estas comunidades estruturam-se fundamentalmente sobre um único aspecto: o interesse em comum de seus membros. A partir deste interesse, as pessoas conseguiriam criar entre si relações sociais independentes do fator físico, e com o tempo essas relações tornar-se-iam de tal forma poderosas que poderiam ser classificadas como laços comunitários. Estruturadas sobre um locus virtual, não físico e nem real, essas comunidades surgiriam através da interação puramente comunicativa entre seus membros. (RECUERO, 2000, p. 4)

Como podemos observar, o acesso às TICs se torna essencial para estabelecer a troca de informações e de diálogo entre as comunidades, proporcionando assim possíveis intercâmbios de ideias que possam favorecer tanto as relações sociais quanto as econômicas e educacionais de um determinado local, promovendo o seu desenvolvimento. Segundo Pereira e Silva (2012), para que haja a mobilização de recursos, as trocas de dados e as experiências, é preciso que ocorra a efetivação de políticas públicas e projetos sociais, havendo a integração entre as organizações e instituições.

Nesse sentido, foi questionado qual(is) instrumento(s) de comunicação e informação que é(são) utilizado(s) pelos agricultores e suas famílias para o acesso às novidades e às notícias nas propriedades, conforme dados apresentados na Tabela 3. 
Tabela 3 - TICs usadas para acessar notícias e novidades.

\begin{tabular}{c|c}
\hline Respostas & Número de Famílias \\
\hline Rádio & 10 \\
\hline Televisão & 5 \\
\hline Conversa com a comunidade & 4 \\
\hline Outros (internet, Facebook e WhatsApp) & 5 \\
\hline Não responderam & 2 \\
\hline
\end{tabular}

Fonte: Os autores, 2017.

No que se refere às respostas obtidas, observamos que 10 agricultores ainda têm como principal meio de comunicação para acesso às informações o rádio; o hábito das conversas com amigos e vizinhos não foram perdidas, pois quatro agricultores responderam que o principal meio de informação ainda está no diálogo; as informações provenientes da televisão foram apontadas por cinco agricultores; um dado relevante encontrado e que evidencia mudanças do comportamento, seria o fato de que cinco agricultores responderam que acessavam a internet ou as redes sociais à procura de informações ou notícias. Na verdade, essa mudança acompanha a realidade virtual da sociedade contemporânea, deixando um pouco as mídias antigas em desuso.

Entretanto, como percebemos, a maioria dos agricultores utiliza o rádio como principal tecnologia para acesso às notícias, isso é explicado pelo fato de que o sinal do rádio nas áreas rurais é eficaz e tem uma grande abrangência. Segundo Weber e Devéns (2010), o rádio é um veículo de comunicação de baixo custo, mobilidade na recepção e o sinal das ondas chegam em regiões remotas, por isso a importância dele em toda a área rural, tanto que era o principal veículo de informação e de trabalho da extensão rural a partir da década de 1960. Ressaltamos o papel da TV e do rádio como expressivo no rural, apesar do surgimento das novas TICs. No entanto, isso acontece em virtude das restrições e da melhor qualidade do sinal das demais tecnologias. Algumas falas trazem essas questões: "As novidades vêm pelo jornal, que não perco um, rádio de manhã cedo, das 7h às 7h15, enquanto trabalho na ordenha." $\mathrm{O}$ termo jornal aqui se refere ao programa de notícias da rádio (Entrevista, 23). "Rádio, TV e fofoca do povo" (Entrevista, 4).

Correlacionando com os dados obtidos acima, perguntamos aos agricultores (aos que responderam sim ao acesso à internet) se eles acessavam as redes sociais e quais seriam as principais redes que teriam contato. Foram citados pelos agricultores o Facebook e o WhatsApp, que têm repercussão de uso mundial em massa; entre os entrevistados, 9 agricultores responderam que usavam esses aplicativos; em contrapartida, 11 agricultores responderam que eles propriamente ditos 
não utilizam as redes, mas atribuíram o uso aos filhos e as esposas. Eis algumas falas que exemplificam essa questão: "Eu uso pouco o face e whats, mas os filhos e a esposa usam bastante" (Entrevista, 22); "Os filhos usam face e o whats" (Entrevista, 21); "A filha tem no celular (internet) [...] A filha usa Facebook" (Entrevista, 15); "Internet via rádio, o sinal é mais ou menos, dá para usar o Facebook e WhatsApp, mas eu não uso, só os filhos quando vÊm. A esposa usa face e whats" (Entrevista, 24).

A partir da recorrência no discurso dos agricultores, ou seja, a alusão ao fato de as redes sociais serem utilizadas principalmente pelos filhos e esposas, analisamos as idades dos entrevistados, e os dados encontrados foram: 21 agricultores acima dos 40 anos; três na média dos 30 anos; e dois não responderam.

Para explicar esse fenômeno, recorremos ao estudioso da área da educação e tecnologia Prensky (2012), que cunhou os termos nativos digitais e imigrantes digitais. Para o autor, os avanços tecnológicos criaram novas dinâmicas e singularidades, assim, a geração que nasceu na era digital, e tem sua vida moldada para a utilização dessas tecnologias no seu dia a dia, são os nativos digitais, a tecnologia integra a vida deles, sendo inseparáveis. Já aqueles indivíduos que durante a vida adulta tiveram que aprender a manusear essas tecnologias têm algumas dificuldades para se adaptar à linguagem da era digital, como o autor exemplifica; em vez de deixar o ensino de forma intuitiva, os imigrantes digitais recorrem aos manuais dos diversos equipamentos e programas.

Nesse contexto, é compreensível a dificuldade dos mais velhos ao fazerem uso das TICs, cabendo aos jovens a vivência e a utilização dessas tecnologias. É nessa perspectiva que os jovens assumem fundamental importância no auxílio do ensino do uso das TICs aos seus pais e avós. As TICs servem como ferramentas para: a disseminação de saberes, o aprimoramento da educação dos jovens; as estratégias que visam assegurar a permanência deste no meio rural; e como transmissor do conhecimento sobre as tecnologias para aqueles que não tiveram acesso a ele.

Redin (2011) corrobora a temática ao afirmar em sua pesquisa que entre as motivações dos agricultores familiares em adquirirem computadores conectados à internet está o fato de haver jovens na propriedade, que a utilizam para fins de estudos (não necessitando se deslocarem até a cidade para o acesso), bem como o estímulo à permanência desses jovens na propriedade. Ainda, o autor traz que os agricultores já utilizam as TICs para acompanhar a meteorologia, lazer e entretenimento.

Segundo Teodoro e Branco (2015), um dos exemplos dos benefícios das informações que a internet oferece para a realidade dos produtores rurais é o processo de aprendizagem e a aplicação dessas informações nas tarefas diárias. De acordo com Páscoa e Gil (2012), o contato com as redes 
sociais proporciona aos idosos acesso a novas relações e interações, o que possibilita a inserção na família (filhos-pais-avós), aproximando as gerações.

Para Sung, Kim e Torres-Gil (2010), a solidariedade entre gerações é de suma importância, pois garante um envelhecimento ativo e com qualidade de vida aos indivíduos. Segundo os autores, os idosos ainda são estereotipados e discriminados, e as trocas e a partilha entre as gerações permitem a construção de uma comunidade mais inclusiva.

A internet também serve como meio de formação profissional, na qual é possível realizar cursos e buscar ferramentas de estudos, bem como material para a produção na propriedade. É importante observar que os agricultores têm interesse em estar conectados com o mundo, devendo ser pensadas ações que possibilitem a qualidade do acesso às redes nessas áreas. Em 2013, uma pesquisa realizada na mesorregião da Fronteira Sul por Gomes dos Santos, Biazus e Coletti, demonstrou que o acesso às TICs no rural traz mudanças significativas, até então em um cenário pouco acessível.

Uma dessas mudanças, como citam Pozenato e Giron (2008), se reflete na cultura das pessoas que vivem no campo, onde há um aumento de suas necessidades em virtude da criação de novas instituições e organizações, e, ao mesmo tempo, essas necessidades mudam, transformam a cultura local. Acrescentando à discussão:

Diante deste quadro da ascensão tecnológica é incontestável a exigência do mercado de trabalho em relação a tais conhecimentos. Além de maciça, ela tem sido responsável por uma verdadeira revolução em nossos hábitos e em nossa organização social, sendo assim, entende-se que é imprescindível que todos os segmentos da sociedade sejam instruídos e estimulados a utilizar as tecnologias não apenas como ferramenta de aprendizagem, mas também como algo que poderá ajudá-los diariamente na organização pessoal ou profissional. (TEODORO; BRANCO, 2015, p. 5147)

Quando proporcionado o acesso adequado com preços justos e qualidade a esses agricultores, as ferramentas que a internet oferece servem como apoio nas relações sociais e na comunicação dentro das redes sociais (WhatsApp, Facebook, Instagram, outros), e também como lazer ao acessar recursos de mídia como vídeos, músicas e filmes (Youtube, Vevo, Google vídeos, entre outros), além dos recursos de pesquisas (Google, bibliotecas virtuais, vídeo aulas, downloads de textos). Assim:

Como um espaço de interação, a rede possibilita, a cada conexão, contatos que proporcionam diferentes informações, imprevisíveis e determinadas por um interesse que naquele momento move a rede, 
contribuindo para a construção da sociedade e direcionando-a. (TOMAÉL; ALCARÁ; DI CHIARA, 2005, p. 94)

Ao realizarmos uma pesquisa breve na bibliografia (SILVA; RODRIGUES; BARROSO, 2013; COUTO; COELHO, 2013; RIZZI et al., 2014), podemos perceber que as políticas públicas sobre Tecnologia de Informação e Comunicação são poucas e geralmente voltadas à população urbana e/ou para as áreas da educação (prioritariamente escolas urbanas). O Plano Diretor de Tecnologia de Informação e Comunicações (PDTIC), instituído no ano de 2017, pretende "contribuir para aumentar a efetividade da geração de benefícios para a sociedade brasileira por meio da expansão do acesso às informações governamentais, da melhoria dos serviços públicos e da ampliação da participação social" (MINISTÉRIO DA CIÊNCIA, TECNOLOGIA, INOVAÇÕES E COMUNICAÇÕES, 2017, p. 96).

No entanto, ao analisa o conteúdo do documento, em nenhum momento foram citadas ações voltadas para a população rural, portanto, a ideia de expansão não parece incluir todas as categorias sociais. Como outro exemplo, citamos o Programa Nacional de Tecnologia Educacional/ ProInfo, que visa:

Promover o uso pedagógico da informática na rede pública de educação básica. O programa leva às escolas computadores, recursos digitais e conteúdos educacionais. Em contrapartida, estados, Distrito Federal e municípios devem garantir a estrutura adequada para receber os laboratórios e capacitar os educadores para uso das máquinas e tecnologias. Para fazer parte do ProInfo Urbano e /ou Rural, o município deve seguir três passos: a adesão, o cadastro e a seleção das escolas. A adesão é o compromisso do município com as diretrizes do programa, imprescindível para o recebimento dos laboratórios. Após essa etapa, deve ser feito o cadastro do prefeito em nosso sistema, que permitirá o próximo passo, que é a inclusão das escolas no ProInfo. (MINISTÉRIO DA EDUCAÇÃO, 2016)

O ProInfo visa à educação em TICs, relacionada ao rural em algum ponto, porém só é acessível a estudantes participantes da escola pública, excluindo os adultos e idosos. Quando afirmamos que o Programa se relaciona em algum ponto com o rural, estamos nos referindo ao fechamento das escolas rurais nos últimos anos e ao deslocamento dos estudantes rurais para as escolas urbanas, onde então se tem acesso à internet e sinal de telefonia. Nesse sentido, o acesso às TICs, na verdade, ocorre na área urbana, onde se encontra a melhor qualidade dos serviços de telefonia e internet, ficando o rural desassistido.

O papel das TICs nos dias atuais tem integrado cada vez mais a sociedade, diminuindo as distâncias e fronteiras, modificando as relações sociais, além de possibilitar a comunicação e a informação de forma dinâmica. Essas mudanças influenciaram o modo de vida social, em que 
aplicativos e sites se tornam os novos elementos de trabalho, lazer e estudos. Como exemplo das facilidades proporcionadas pelas TICs, podemos citar que antes uma simples tarefa, como pagar uma conta, demandava que o indivíduo se deslocasse de sua casa até uma agência bancária. hoje, ele pode acessar de sua casa pelo smartphone e em poucos segundos é feito o pagamento da fatura.

Quando estendemos o exemplo acima para a área rural, teremos que a distância de um centro de pagamento, geralmente situado no urbano, fica a longas distâncias da propriedade, demandando uma grande parcela de tempo. Sendo assim, essas ferramentas on-line auxiliariam diminuindo o tempo de deslocamento desse agricultor, proporcionando dessa forma espaço para outras atividades.

A incorporação dessa tecnologia deve ocorrer mais cedo ou mais tarde, tanto para os produtores de grande escala quanto para os agricultores familiares, porém a incorporação para os produtores menores torna-se mais difícil. Esse fato, de acordo com Freitas (2013), acontece devido à falta de recursos dos agricultores, e quando têm verba, não possuem orientação e conhecimento para utilizá-la.

Para que a sustentabilidade seja efetivada em todas as suas dimensões, é necessária a inclusão das áreas rurais nos serviços de qualidade relativos à internet e à telefonia. Porém, como demonstramos anteriormente, além dos fatores citados, o acesso a esses meios de comunicação muitas vezes são inexistentes ou ineficazes, e as políticas públicas e as ações do Estado priorizam as áreas urbanas.

\section{Algumas considerações}

Diante do exposto, podemos concluir que o rural do município de Saudade do Iguaçu ainda apresenta dificuldades ao acesso às Tecnologias de Comunicação e Informação, no que tange ao sinal da telefonia e de internet. Em relação à telefonia, apenas uma empresa foi citada, as demais operadoras não possuem sinal na área rural do município, fazendo com que os agricultores familiares fiquem reféns do monopólio telefônico. Uma parcela considerável ainda não possui acesso à internet ou, quando têm, o sinal muitas vezes é ruim, além da maioria da transmissão do sinal da rede ser feita via rádio. Por essas dificuldades, as informações também, em sua maioria, são recebidas por rádio e televisão, ficando aquém da realidade dos centros urbanos que, com o acesso facilitado às TICs, possuem uma mobilidade maior na comunicação e informação entre os indivíduos.

A questão do acesso às TICs não somente está vinculada ao bem-estar das populações rurais, mas tem seu papel fundamental como estratégia para a permanência e reprodução da agricultura familiar e do exercício da democracia plena. De acordo com Almeida, Bautista e Addor (2017), o 
uso das tecnologias de informação e comunicação é essencial no campo da democracia participativa, e a desigualdade ao acesso a essas ferramentas impossibilitam o exercício da democracia e a consciência cidadã. Para que se tenha uma participação qualificada é necessário estabelecer a igualdade de direitos, seja ela real ou virtual, e para isso é indispensável a construção e efetivação de políticas de inclusão e institucionalização dos espaços digitais.

É verdade que ao desassistir as áreas rurais no que se refere ao acesso às Tecnologias de Comunicação e Informação o elemento social da sustentabilidade fica enfraquecido e o desenvolvimento sustentável comprometido. Assim, não basta apenas procurarmos alternativas econômicas e ambientais mais sustentáveis, é de suma importância incluir o elemento humano nessa conta, pois, se não o fizermos, continuaremos falando infinitamente sobre como alcançar a sustentabilidade. Da mesma forma, não adianta pesquisarmos e debatermos sobre a reprodução da agricultura familiar no campo, pois se o direito ao acesso às tecnologias do mundo globalizado não forem contempladas, voltamos à questão da inserção do elemento humano e da sua qualidade de vida na equação econômica e ambiental da sustentabilidade.

Para um desenvolvimento rural sustentável da sociedade é imprescindível que o país possua capacidade de compreender a necessidade desse direito e de expandir as políticas públicas de melhoria do serviço e acesso às TICs nas áreas rurais. Esse reconhecimento significa também pensar em ações voltadas para a inclusão digital para adultos e idosos que residem nessas áreas, nesse sentido:

A aprendizagem é promovida pelo compartilhamento e o uso da informação, os quais, como resultado, possibilitam novos aportes, entre eles os mais significativos são os novos conhecimentos e as novas habilidades. As redes que constituem espaços em que o compartilhamento da informação e do conhecimento é proficiente e natural são espaços também de aprendizagem e, assim, tornam-se um ambiente para o desenvolvimento e para a inovação. (TOMAÉL; ALCARÁ; DI CHIARA, 2005, p. 102)

Aprender e conhecer é direito de todo o cidadão, bem como o acesso às formas de comunicação, informação e das atuais tecnologias, pois esses elementos fazem parte do processo e da dinâmica da sociedade digital e virtual em que vivemos. Além disso, é a partir da inovação, participação e da construção de ideias que as populações podem constituir a sustentabilidade. Partimos do pressuposto de que esse tema para o paradigma do desenvolvimento sustentável não foi exaurido neste trabalho, porém esperamos ter contribuído com a discussão sobre a dimensão social da sustentabilidade vinculada ao acesso às de Comunicação e Informação nas áreas rurais. 


\section{Referências bibliográficas}

ABREU, M. K. F. de et al. Protagonismo social e suas contribuições para o desenvolvimento rural sustentável: um estudo de caso no município de Caririaçu - Ceará (Brasil) Sustentabilidade em Debate - Brasília, Edição Especial, v. 7, p. 152-168, 2016.

ALMEIDA, L. R. M. de; BAUTISTA, J. B.; ADDOR F. Potencialidades e limites do uso da tecnologia para o aprofundamento da democracia. Revista Tecnologia e Sociedade, Curitiba, v. 13, n. 27, p. 208-226, jan./abr. 2017.

ALMEIDA, J. Da ideologia do progresso à ideia de desenvolvimento (rural) sustentável. In: ALMEIDA, J.; NAVARRO, Z. Reconstruindo a agricultura: ideias e ideais na perspectiva do desenvolvimento rural sustentável. 3. ed. Porto Alegre: Editora da UFRGS, p. 33-55, 2009.

FOLHA DE SÃO PAULO. Anatel quer cassar licenças de telefonia celular na área rural. São Paulo, 7 jul. de 2017. Disponível em: http://www1.folha.uol.com.br/mercado/2017/07/1899152-anatel-qu er-cassar-licencas-de-telefonia-celular-na-area-rural.shtml. Acesso: 20 nov. de 2017.

BRASIL. Ministério da Educação. Programa Nacional de Tecnologia Educacional/ProInfo. Disponível em: http://portal.mec.gov.br/proinfo/ proinfo. Acesso em: 9 out. de 2017.

BRASIL. Ministério da Ciência, Tecnologia, Inovações e Comunicações. Secretaria Executiva Diretoria de Tecnologia da Informação. Plano diretor de Tecnologia da informação e comunicações (PDTIC). 2017. Disponível em: http://www.mctic.gov.br/mctic/opencms/transpa rencia/Acoes_e_Programas.html. Acesso em: 16 de jan. de 2018.

CASTELLS, M. A era da informação: economia, sociedade e cultura. São Paulo: Paz e Terra, 1999.

CASTRO, B. L. G. de; BERNARTT, M. de L.; GODOY, C. M. T. A Tecnologia de Informação e Comunicação como mecanismo para a migração: um estudo sobre os haitianos no Brasil. DRd - Desenvolvimento Regional em debate, v. 7, n. 2, p. 158-172, jul./dez. 2017.

COMISSÃO MUNDIAL SOBRE MEIO AMBIENTE E DESENVOLVIMENTO. Nosso Futuro Comum. Rio de Janeiro: Editora da Fundação Getúlio Vargas, 1988.

COUTO, M. E. S; COELHO, L. Políticas públicas para inserção das TIC nas escolas: algumas reflexões sobre as práticas. Colabor@ - Revista Digital de CVA - Ricesu, v. 8, n. 30, p. 1-11, 2013.

FELIZOLA, P. A. M. O direito à comunicação como princípio fundamental: internet e participação no contexto da Sociedade em Rede e políticas 
públicas de cesso à internet no Brasil. Revista de Direito, Estado e Telecomunicações, v. 3, n. 1, p. 205-289, 2011.

FELIPPI, A. C. T.; ESCOSTEGUY, A. C. D. Juventude rural e novas formas de sociabilidade: um estudo do uso do celular no Sul do Brasil. Revista Latinoamericana de Ciencias de La Comunicacion, v. 14, n. 16, 2017.

FILHO, J. S. P. Alternativas de Políticas Públicas Para a Banda Larga. Câmara dos deputados, Consultoria Legislativa, Brasília, 2009.

FOLADORI, G. Avanços e limites da sustentabilidade social. Revista Paranaense de Desenvolvimento, Curitiba, n. 102, p. 103-113, jan./jun. 2002.

FREITAG, R. Internet rural muda a vida de famílias de agricultores. Palmitos, 2011. Disponível em: https://www.palmitos.sc.gov.br/noticias/ index/ver/codMapaItem/8509/codNoticia/30102\#.VBZFvGNC9VI. Acesso em: 6 ago. de 2017.

FREITAS, G. S. Tecnologia No Setor Agrícola Brasileiro: Um Olhar Sob A Ótica Da Teoria Evolucionária. Revista Eletrônica de Administração e Turismo - ReAT, v. 2, n. 1, jan./jun. 2013.

FUJISAWA, D. S. Utilização de jogos e brincadeiras como recurso no atendimento fisioterapêutico de criança: implicações na formação do fisioterapeuta. 2000. 147 f. Dissertação (Mestrado em Educação) - Faculdade de Filosofia e Ciências, Universidade Estadual Paulista, Marília, 2000.

GOMES DOS SANTOS, J. L.; BIAZUS, M. do C.; COLETTI, T. A internet nas comunidades rurais da Mesorregião Fronteira Sul: acesso e mudanças na visão da juventude da agricultura familiar. In: Seminário de Ensino, Pesquisa e Extensão da Universidade Federal da Fronteira do Sul (SEPE-UFFS), Anais..., v. 3, n. 1, out. 2013. Disponível em: https:// periodicos.uffs.edu.br/index.php/SEPE-UFFS/article/view / 494. Acesso em: 30 dez. de 2017.

INSTITUTO PARANAENSE DE DESENVOLVIMENTO ECONÔMICO E SOCIAL - IPARDES. Caderno Estatístico Município de Saudade do Iguaçu. Disponível em: http://www.ipardes.gov.br/cadernos/MontaCadPdf1.php? Municipio=85568. Acesso em: 15 out. de 2017.

LAMARCA, D. S. F. et al. A Relevância do Uso das Tecnologias de Informação e Comunicação (TIC) nos Projetos de Extensão Sediados na UNESP - Campus De Tupã. Sustentabilidade e Responsabilidade Social, v. 3. Belo Horizonte: Editora Poisson, 2017.

LEITE, F. P. A; FIORILLO, C. A. P. Sustentabilidade no meio ambiente cultural - o exercício da liberdade de expressão na sociedade da informação. Veredas do Direito, v. 13, n. 26, p. 337-360, mai./ago. 2016.

LINCOLN, Y. S.; GUBA, E. G. Naturalistic inquiry. Nova Iorque: Sage, 1991. 
MATA, A. Como funciona a internet via rádio? 2016. Disponível em: https://www.oficinadanet.com.br/post/10234-como-funciona-a-inter net-via-radio. Acesso em: 20 nov. 2017.

NEIVA, J. L. Proposição de Indicadores de Desenvolvimento Sustentável para Assentamentos Rurais. Economia Política do Desenvolvimento, v. 1, n. 7, p. 83-106, 2010.

PÁSCOA, G.; GIL, H. O desafio do Facebook na promoção do envelhecimento ativo e da solidariedade intergeracional. In: Congresso Internacional de Gerontologia e Geriatria, 3., 2012, Lisboa. Disponível em: https://repositorio.ipcb.pt/handle/10400.11/2047. Acesso em: 10 jan. 2018.

PEREIRA, D. M; SILVA, G. S. As Tecnologias de Informação e Comunicação (TICs) como aliadas para o desenvolvimento. Cadernos de Ciências Sociais Aplicadas, ano 7, n. 8, jul./dez., 2012.

POZENATO, K. M. M; GIRON, L. S. Novas Tecnologias nas comunidades rurais: TV e internet na colônia do RS. Conexão - Comunicação e Cultura, v. 7, n. 13, jan./jun. 2008.

PRENSKY, M. Digital natives, digital immigrants part 1. On the horizon, v. 9, n. 5, p. 1-6, 2001. Disponível em: https://www.emerald. com/insight/content/doi/10.1108/10748120110424816/full/html.

Acesso em: 15 dez. 2017.

RECUERO, R. da C. A internet e a nova revolução na comunicação mundial. Pontifícia Universidade Católica do Rio Grande do Sul, 2000. Disponível em: http://www.raquelrecuero.com/revolucao.htm. Acesso: $30 \mathrm{dez}$. 2017.

REDIN, E. Entre o produzir e o reproduzir na agricultura familiar fumageira de Arroio do Tigre/RS. 2011. 262 f. Dissertação (Mestrado em Extensão Rural) - Universidade Federal de Santa Maria, Santa Maria, 2011.

RIBEIRO, J.; SOUZA, F. N de; LOBÃO, C. Saturação da Análise na Investigação Qualitativa: Quando Parar de Recolher Dados?. Revista Pesquisa Qualitativa, v. 6, n. 10, p. iii-vii, abr. 2018.

RICOY, M. C.; COUTO, M. J. V. S. As boas práticas com TIC e a utilidade atribuída pelos alunos recém-integrados à universidade. Educação $e$ Pesquisa, São Paulo, v. 40, n. 4, p. 897-912, out./dez. 2014.

RIZZI, C. B. et al. Políticas Públicas e o uso das TICs na educação para o trânsito: uma ênfase nas ações do projeto TESC. In: Seminário Nacional Estado e Políticas sociais, 6., Seminário de Direitos Humanos, 2. Anais... Unioeste, 2014.

ROCHA, L. A; KHAN, A. S.; LIMA, P. V. P.; SOUSA, E. P. de A importância da política de inovação no desenvolvimento da agricultura brasileira. 
Estudos Sociedade e Agricultura, Rio de Janeiro, v. 22, n. 1, p. 224-246, 2014.

SACHS, I. Estratégias de Transição para do século XXI - Desenvolvimento e Meio Ambiente. São Paulo: Studio Nobel - Fundação para o desenvolvimento administrativo, 1993.

SILva, J. A. B da; RODRIGUeS, A. de J.; BARROSO, R. de C. A. Políticas públicas de TIC e a formação de professores. GT5 - educação, comunicação e tecnologias. Encontro Internacional de Formação de Professores, 5., Anais..., 2013.

SUNG, K.; KIM, B.; TORRES-GIL, F. Respectfully treating the elderly: affective and behaviour always of American Young adults. Educacional Gerontology, v. 36, p. 127-147, 2010.

TAKAHASHI, T. (Org.). Sociedade da informação no Brasil: livro verde. Brasília, DF: Ministério da Ciência e Tecnologia, 2000.

TEODORO, P. G.; BRANCO, E. S. O uso da internet como recurso de apoio ao trabalho desenvolvido pelas comunidades rurais. In: XII Congresso Nacional de Educação/EDUCERE, Curitiba, 2015. Anais... v. 1. p. 51465161, 2015.

TOMAÉL, M. I.; ALCARÁ, A. R.; DI CHIARA, I. G. Das redes sociais à inovação. Ciência da Informação, Brasília, v. 34, n. 2, p. 93-104, mai./ago. 2005.

VIERO, V. C.; SILVEIRA, A. C. M. da. Apropriação de Tecnologias de Informação e Comunicação no Meio Rural Brasileiro. Cadernos de Ciência E Tecnologia, Brasília, v. 28, n. 1, p. 257-277, jan./abr. 2011.

WEBER, A. F.; DEVÉNS, P. O rádio no meio rural: consumo de programas radiofônicos rurais por agricultores do Rio Grande do Sul. Rádio-leituras, ano I, n. 1, p. 41-59, jul./dez. 2010.

WAMMES, L. T.; PASTÓRIO, I. T.; ROESLER, M. R. von B. O meio rural e as novas perspectivas para o desenvolvimento sustentável. In: Jornada Questão Agraria e Desenvolvimento, 2., Universidade Federal do Paraná, 2013. Disponível em: http://www.jornadaquestaoagraria.ufpr.br/ trabalhos/uploads/omeioruraleasnovasperspectivasparaodesenvolvim entosustent_avel.docvers_eoquasefinal1.pdf. Acesso em: 10 nov. 2018.

LORA, Mayza Izadora; GODOY, Cristiane Maria Tonetto; GODOY, Wilson Itamar; MARINI, Marcos Junior. Tecnologias de Informação e Comunicação, o outro viés da sustentabilidade: um olhar para o rural do município de Saudade do Iguaçu (PR). Estudos Sociedade e Agricultura, v. 27, n. 1, p. 185-206, fev. 2019. 
Resumo: (Tecnologias de Informação e Comunicação, o outro viés da sustentabilidade: um olhar para o rural do município de Saudade do Iguaçu (PR)). O desenvolvimento sustentável preconiza a equidade das dimensões sociais, ambientais e econômicas, uma vez que este é um processo complexo e multidimensional. O elemento social é de suma importância para o alcance da sustentabilidade, pois vivemos em uma sociedade baseada nas Tecnologias de Informação e Comunicação (TICs), trazendo ao cenário social as tecnologias em ritmo acelerado e contribuindo para a construção de uma comunicação ágil e eficaz. A tecnologia e o acesso à comunicação são direitos da população; na falta dessa disponibilização surgem desafios e lutas para garantir o acesso às TICs. Nesse sentido, o presente artigo tem como objetivo compreender a percepção dos agricultores familiares do município de Saudade do Iguaçu, Paraná, no que se refere à qualidade e ao acesso às TICs no meio rural e à importância desses serviços na reprodução social e no desenvolvimento rural sustentável. A metodologia escolhida foi a qualitativa, sendo realizadas 26 entrevistas semiestruturadas com os agricultores do município. Concluimos que o rural do município de Saudade do Iguaçu ainda apresenta dificuldades ao acesso às TICs, no que tange ao sinal da telefonia e de internet. Ainda, a realidade do município demonstra o papel direto das TICs para os jovens rurais, que auxiliam os pais a utilizá-las, e como estratégia para a permanência e reprodução da agricultura familiar. Portanto, para que haja o acesso de qualidade das TICs nas áreas rurais devem ser pensadas estratégias e políticas públicas de expansão do sinal digital e ações de inclusão digital para adultos e idosos.

Palavras-chave: Tecnologias de Informação e Comunicação; agricultura familiar; desenvolvimento rural sustentável; acessibilidade; sustentabilidade social.

Abstract: (Information and Communication Technologies, the other bias of sustainability: a look at the rural county of Saudade do Iguaçu (PR)). The sustainable development advocates the equity of social, environmental and economic dimensions, since development is a complex and multidimensional process. The social elements have a great importance for the achievment of sustainability, since we live in a society based on Information and Communication Technologies (ICTs). They bring technologies to the social scene at a fast pace, contributing to the construction of an agile and effective comunication. Technology and Access to comunication are rights of the population and the absence of this availability result in challenges and fights to guarantee the Access to ICTs. In this sense, the present paper aims to understand the perception of family farmers of the county of Saudade do Iguaçu, Paraná, regarding 
the quality and Access of the ICTs, as well as the importance of these services in social reproduction and in the sustainable rural development. The chosen methodology was the qualitative, through twenty nine semistructured interviews with the farmers. As conclusion, we sugered that the rural of Saudade do Iguaçu still presents difficulties to Access the ICTs, on telephony and internet signal. However, the reality of that county demonstrated the direct importance of ICTs for the rural youth, in its role to help the parents to use the ICTs and as strategy to the permanence and reproduction of family agriculture. Thinking the sustainable rural development require to recognize social elements and accept that the ICTs are necessary tools for sustainability. So, ICTs quality access in the rural áreas is important to strategies and public policies to the expansion of digital signal and actions to the digital inclusion for adults and aged.

Keywords: Information and Communication Technologies; family agriculture; sustainable rural development; Access; social sustainability.

Recebido em julho de 2018. Aceito em janeiro de 2019. 